\title{
The influence of capping layers on pore formation in Ge during ion implantation
}

H. S. Alkhaldi, Tuan T. Tran, F. Kremer, and J. S. Williams

Citation: Journal of Applied Physics 120, 215706 (2016); doi: 10.1063/1.4969051

View online: https://doi.org/10.1063/1.4969051

View Table of Contents: http://aip.scitation.org/toc/jap/120/21

Published by the American Institute of Physics

\section{Articles you may be interested in}

Suppression of ion-implantation induced porosity in germanium by a silicon dioxide capping layer Applied Physics Letters 109, 082106 (2016); 10.1063/1.4961620

Synthesis of $\mathrm{Ge}_{1-\mathrm{x}} \mathrm{Sn}_{\mathrm{x}}$ alloys by ion implantation and pulsed laser melting: Towards a group IV direct bandgap material

Journal of Applied Physics 119, 183102 (2016); 10.1063/1.4948960

Migration processes of the As interstitial in GaAs

Journal of Applied Physics 120, 215705 (2016); 10.1063/1.4969049

Porosity as a function of stoichiometry and implantation temperature in $\mathrm{Ge} / \mathrm{Si}_{1-\mathrm{x}} \mathrm{Ge}_{\mathrm{X}}$ alloys

Journal of Applied Physics 119, 094303 (2016); 10.1063/1.4942995

Threshold switching and electrical self-oscillation in niobium oxide films

Journal of Applied Physics 120, 124102 (2016); 10.1063/1.4963288

Ion implantation damage and annealing in germanium

Journal of Applied Physics 54, 2295 (1983); 10.1063/1.332385

\section{PHYSICS TODAY}

MANACER'S GUIDE

WHITEPAPERS
Accelerate R\&D with

Multiphysics Simulation

\section{READ NOW}

PRESENTED BY

৩ $\subset$ M 


\title{
The influence of capping layers on pore formation in Ge during ion implantation
}

\author{
H. S. Alkhaldi, ${ }^{1,2}$ Tuan T. Tran, ${ }^{1}$ F. Kremer, ${ }^{3}$ and J. S. Williams ${ }^{1}$ \\ ${ }^{1}$ Department of Electronic Materials Engineering, Research School of Physics and Engineering, \\ The Australian National University, Canberra, Australian Capital Territory 2601, Australia \\ ${ }^{2}$ Department of Physics, College of Education-Jubail, Dammam University, Dammam 1982, Saudi Arabia \\ ${ }^{3}$ Centre for Advanced Microscopy, The Australian National University, Australian Capital Territory 2601, \\ Australia
}

(Received 2 August 2016; accepted 15 November 2016; published online 2 December 2016)

\begin{abstract}
Ion induced porosity in Ge has been investigated with and without a cap layer for two ion species, $\mathrm{Ge}$ and $\mathrm{Sn}$, with respect to ion fluence and temperature. Results without a cap are consistent with a previous work in terms of an observed ion fluence and temperature dependence of porosity, but with a clear ion species effect where heavier $\mathrm{Sn}$ ions induce porosity at lower temperature (and fluence) than Ge. The effect of a cap layer is to suppress porosity for both $\mathrm{Sn}$ and Ge at lower temperatures but in different temperatures and fluence regimes. At room temperature, a cap does not suppress porosity and results in a more organised pore structure under conditions where sputtering of the underlying Ge does not occur. Finally, we observed an interesting effect in which a barrier layer of a-Ge that is denuded of pores formed directly below the cap layer. The thickness of this layer $(\sim 8 \mathrm{~nm})$ is largely independent of ion species, fluence, temperature, and cap material, and we suggest that this is due to viscous flow of a-Ge under ion irradiation and wetting of the cap layer to minimize the interfacial free energy. Published by AIP Publishing.

[http://dx.doi.org/10.1063/1.4969051]
\end{abstract}

\section{INTRODUCTION}

Germanium (Ge) has become an increasingly important material for a range of applications in microelectronic devi$\operatorname{ces}^{1}$ due to higher carrier mobility and smaller bandgap than silicon (Si). Doping Ge with high Sn concentration has also opened up applications for Ge-Sn photonics. ${ }^{2}$ However, in all such applications that rely on ion implantation doping of $\mathrm{Ge}$, the formation of a porous layer on the Ge surface is a significant issue and must be avoided or minimized. ${ }^{3}$ For example, the formation of porosity in Ge has been reported to occur during ion implantation of crystalline $\mathrm{Ge}$ at room temperature (RT) at quite moderate implant fluences. It results in significant surface morphology associated with volumetric swelling and the formation of amorphous porous layers. ${ }^{4-6}$ This affect has been observed for a wide range of heavy ions at $\mathrm{keV}$ energies and occurs at a threshold fluence of around $10^{15}$ ions $/ \mathrm{cm}^{2}{ }^{7-9}$ Although deleterious for many microelectronic applications, such nanoporous structures with nm scale can have wide applications including in lithium ion batteries as an anode, ${ }^{10}$ in gas sensors, ${ }^{11}$ in thermoelectric applications, ${ }^{12}$ and even in specific optoelectronic applications. ${ }^{13}$ Most of the previous studies on porosity in irradiated Ge have focused on the evolution and understanding of porous structures quantitatively and qualitatively. Up to now, few studies have focused on studying the suppression of a porous structure. Generally, based on literature reports, porosity is often suppressed at liquid nitrogen implantation temperature $\left(\mathrm{LN}_{2} \mathrm{~T}\right)$ for most heavy ion implant species. Holland et al. ${ }^{14}$ found that implanting $\mathrm{Bi}^{+}$into $\mathrm{Ge}$ at $\mathrm{LN}_{2} \mathrm{~T}$ could suppress the pore formation at fluences up to $4 \times 10^{15}$ ions $/ \mathrm{cm}^{2}$. Stritzker et al. ${ }^{5}$ also observed that a porous structure was eliminated at $\mathrm{LN}_{2} \mathrm{~T}$ for self-ion implantation of Ge even at high fluences up to $1 \times 10^{17} \mathrm{ions} / \mathrm{cm}^{2}$. Our previous results ${ }^{15}$ support this latter conclusion for selfion irradiation of both $\mathrm{Ge}$ substrates and $\mathrm{Si}_{1-\mathrm{x}} \mathrm{Ge}_{\mathrm{x}}$ alloys even at fluences higher than $1 \times 10^{17} \mathrm{ions} / \mathrm{cm}^{2}$. However, for some ion species, porous structures or surface microstructural features have been observed in Ge even at $\mathrm{LN}_{2} \mathrm{~T}$. For example, Holland et al. ${ }^{14}$ detected blackening on the surface at a fluence of $3 \times 10^{16}$ ions $/ \mathrm{cm}^{2}$ when implanting with $120 \mathrm{keV} \mathrm{Sn}^{+}$ions, which is indicative of structural changes in Ge, but they did not show any TEM images of the microstructure. Similarly, recent work by Tran et al. ${ }^{2}$ observed porous structures by implanting $100 \mathrm{keV} \mathrm{Sn}^{+}$ions with fluences between $2.5 \times 10^{16}$ and $5 \times 10^{16}$ ions $/ \mathrm{cm}^{2}$ for $\mathrm{Sn}^{+}$at $\mathrm{LN}_{2} \mathrm{~T}$. This is consistent with the finding of Bruno et al., ${ }^{16}$ who observed a honeycomb-like structure for antimony ( $\mathrm{Sb}$ ) implanted $\mathrm{Ge}$ at $\mathrm{LN}_{2} \mathrm{~T}$ to a fluence of $6.4 \times 10^{15} \mathrm{ions} / \mathrm{cm}^{2}$ at $50 \mathrm{keV}$. Clearly, these reports show that for some heavy ion species, $\mathrm{LN}_{2} \mathrm{~T}$ bombardment does not suppress porosity.

In terms of capping the Ge surface prior to implantation, as a possible means of suppressing porosity, there have been few previous studies. Appleton et al. ${ }^{8}$ revealed that the free surface of Ge is not necessary for initial void nucleation after coating the surface with an aluminum (Al) film of $\sim 80 \mathrm{~nm}$ and then implanting $230 \mathrm{keV} \mathrm{Ge}^{+}$at $\mathrm{RT}$ with a fluence of $2 \times 10^{16}$ ions $/ \mathrm{cm}^{2}$. They observed that a porous structure still formed underneath the cap layer and concluded that the initial crater formation is not a sputtering process as suggested by Wilson, ${ }^{4}$ but relates to vacancy agglomeration at the $\mathrm{Ge}$ surface under a cap. In addition, Janssens et al. ${ }^{17}$ also deposited a thin $\mathrm{SiO}_{2}$ film on the surface prior to implantation at 
RT with $\mathrm{Sb}$, arsenic (As), and gallium (Ga) ions at keV energies. At fluences between $1 \times 10^{15}$ and $3 \times 10^{15}$ ions $/ \mathrm{cm}^{2}$, they found that subsurface void formation and porosity cannot be suppressed for $\mathrm{Sb}$ ions by using a cap layer, but no porous structure was observed for As and Ga ions, although it is unclear whether porosity occurred for Ga and As ions without a cap. They also suggested that voids form as a result of vacancy clustering, not sputtering, and thus, the Ge expands beneath the oxide layer. Although not specifically examining a cap layer on Ge for suppression of porosity, Darby et al. ${ }^{18,19}$ examined the effect of deposited Ge layers on both $\mathrm{Ge}$ and $\mathrm{SiO}_{2}$. They found that depositing an evaporated $\mathrm{Ge}$ film onto thermally grown layers of $\mathrm{SiO}_{2}$ results in the formation of a normal columnar (porous) structure, whereas in sputtered Ge films voids develop and expand isotropically. The specific location of the nucleation sites for pore formation in such deposited films is likely to cause this change in morphology. It is noteworthy that, in both sputtered and evaporated films, a continuous a-Ge layer of $\sim 8 \mathrm{~nm}$ thickness on top of the porous structure was found to be devoid of pores.

In contrast to these previous RT studies with a capping layer, where porosity was still observed, Tran $e t a l^{2}$ found that a capping layer of $20 \mathrm{~nm}$ thick $\mathrm{SiO}_{2}$ prior to implantation at $\mathrm{LN}_{2} \mathrm{~T}$ with $\mathrm{Sn}^{+}$ions completely suppressed the porous structure. Presumably, the different implant temperature is responsible for this favorable result, which is thought to be a result of low mobility of point defects in this low temperature regime, combined with the behavior of a cap layer as an obstacle for vacancy clustering, thus preventing the pore formation. $^{2}$

In the current study, we have focused on examining the effect of a cap layer on pore formation with respect to ion fluence, temperature, thickness of the cap layer, and ion species. We found that a cap layer can suppress porosity in $\mathrm{Ge}$ in some cases, depending on the irradiation temperature and ion mass. In addition, even when a porous structure develops, there is a continuous a-Ge layer of $\sim 8 \mathrm{~nm}$ thickness immediately under the cap that is denuded of pores, and we discuss this in terms of a wetting phenomenon of the a-Ge due to its viscous flow under the cap.

\section{EXPERIMENTAL METHODS}

Undoped crystalline Ge wafers of (100) orientation were used as substrates. Various capping layers of $\mathrm{SiO}_{2}, \mathrm{Al}$, and amorphous $\mathrm{Si}(\mathrm{a}-\mathrm{Si})$ were used prior to ion bombardment. A $\mathrm{SiO}_{2}$ cap layer was deposited onto selected $\mathrm{Ge}$ samples with thicknesses of $20 \mathrm{~nm}$ and $40 \mathrm{~nm}$. The deposition of both the $\mathrm{SiO}_{2}$ and a-Si cap layers was carried out using plasma enhanced chemical vapour deposition (PECVD). The deposition rate was $58 \mathrm{~nm} / \mathrm{min}$ at a temperature of $300^{\circ} \mathrm{C}$. For an $\mathrm{Al}$ cap layer, we used an e-beam evaporator. The thickness of a-Si and $\mathrm{Al}$ cap layers was $40 \mathrm{~nm}$.

All the above $\mathrm{Ge}$ and $\mathrm{SiO}_{2}$ capped samples were then implanted with $140 \mathrm{keV} \mathrm{Ge}^{-}$ions and $225 \mathrm{keV} \mathrm{Sn}^{+}$ions at the ANU Heavy Ion Accelerator Facility. For Al and a-Si capped samples, $140 \mathrm{keV} \mathrm{Ge}^{-}$ions were implanted at RT. To minimise channelling effects, the sample holder was misoriented by $7^{\circ}$ to the normal beam direction and ion fluences up to $2 \times 10^{16}$ ions $/ \mathrm{cm}^{2}$ were used. The sample holder temperatures varied between $-180^{\circ} \mathrm{C}$ and $100^{\circ} \mathrm{C}$ and were held constant during irradiation with a deviation of $\pm 3{ }^{\circ} \mathrm{C}$, achieved by connecting a $\mathrm{CrAl}$ thermocouple to the sample holder. The average ion flux for $\mathrm{Ge}$ ions and $\mathrm{Sn}$ ions was $\sim 1.2 \times 10^{13} \mathrm{ions} / \mathrm{cm}^{2} / \mathrm{s}$ and $6.9 \times 10^{11} \mathrm{ions} / \mathrm{cm}^{2} / \mathrm{s}$, respectively. Part of the sample was masked using a $\mathrm{Si}$ wafer to provide a well-defined edge between the irradiated and the non-irradiated areas.

According to SRIM simulation, ${ }^{20}$ the projected ion range, the longitudinal straggling, the energy loss (nuclear and electronic), the sputtering yield, and the maximum production depth for vacancies under the irradiation conditions are summarized in Table I. Compared with nuclear energy loss, the electronic energy loss is negligible at the implantation energies, which were chosen to obtain a similar projected range $\mathrm{R}_{\mathrm{p}}$ for both Ge and $\mathrm{Sn}$ ions.

A Dektak stylus profilometer was used to determine the step height between the unimplanted and the implanted regions. A plan-view of the sample surface was obtained using plan-view scanning electron microscopy (PVSEM) with a Zeiss-UltraPlus field effect (FE) SEM. The structure underneath the surface was observed by cross-sectional transmission electron microscopy (XTEM), which was performed with a Philips CM300 microscope operating at $300 \mathrm{keV}$. An elemental concentration map under the capping layer was investigated by using energy dispersive $\mathrm{X}$-ray (EDX) analysis with a JEOL $2100 \mathrm{~F}$ instrument.

\section{RESULTS}

In Fig. 1, we illustrate by XTEM typical behaviour of $\mathrm{Ge}$ bombarded with $\mathrm{Ge}^{-}$and $\mathrm{Sn}^{+}$ions at $\mathrm{LN}_{2} \mathrm{~T}$, including the use of a $\mathrm{SiO}_{2}$ cap prior to $\mathrm{Sn}$ ion bombardment. Self-ion implantation of Ge at $\mathrm{LN}_{2} \mathrm{~T}$, even for fluences up to $1 \times 10^{17} \mathrm{ions} / \mathrm{cm}^{2}$, produces a thick a-Ge layer but no pore formation was observed as shown in Fig. 1(a). In contrast, similar to the work of Tran et al., ${ }^{2} \mathrm{LN}_{2} \mathrm{~T}$ does not suppress the porous structure when implanting $\mathrm{Sn}$ with a lower fluence of $3 \times 10^{16} \mathrm{ions} / \mathrm{cm}^{2}$, as can be seen in Fig. 1(b). In this case, the top $2 / 3 \mathrm{rd}$ of the a-Ge layer contains large columnar pores that intersect the surface, consistent with

TABLE I. Projected ion Range $\mathrm{R}_{\mathrm{p}}$, longitudinal straggling $\Delta \mathrm{R}_{\mathrm{p}}$, Nuclear energy loss $(\mathrm{dE} / \mathrm{dx})_{\text {nucl }}$, electronic energy loss $(\mathrm{dE} / \mathrm{dx})_{\mathrm{el}}$, maximum vacancy production depth, and sputtering yield for $140 \mathrm{keV} \mathrm{Ge}^{+}$and $225 \mathrm{keV} \mathrm{Sn}^{+}$implanted into Ge, from SRIM simulations. ${ }^{25}$

\begin{tabular}{|c|c|c|c|c|c|c|c|c|}
\hline Target & $\begin{array}{l}\text { Energy } \\
(\mathrm{keV})\end{array}$ & $\begin{array}{c}\text { Ion } \\
\text { species }\end{array}$ & $\begin{array}{l}\mathrm{R}_{\mathrm{p}} \\
(\mathrm{nm})\end{array}$ & $\begin{array}{l}\Delta \mathrm{R}_{\mathrm{p}} \\
(\mathrm{nm})\end{array}$ & $\begin{array}{l}(\mathrm{dE} / \mathrm{dx})_{\mathrm{el}} \\
(\mathrm{keV} / \mathrm{nm})\end{array}$ & $\begin{array}{c}(\mathrm{dE} / \mathrm{dx})_{\text {nucl }} \\
(\mathrm{keV} / \mathrm{nm})\end{array}$ & $\begin{array}{c}\text { Maximum vacancy } \\
\text { production depth }(\mathrm{nm})\end{array}$ & $\begin{array}{l}\text { Sputtering yield } \\
\text { atom/ion }\end{array}$ \\
\hline $\mathrm{Ge}$ & 140 & $\mathrm{Ge}$ & 62.2 & 30.1 & 0.2 & 1.5 & 27.2 & 4.2 \\
\hline $\mathrm{Ge}$ & 225 & Sn & 65.1 & 25.8 & 0.2 & 2.8 & 32.7 & 5.7 \\
\hline
\end{tabular}




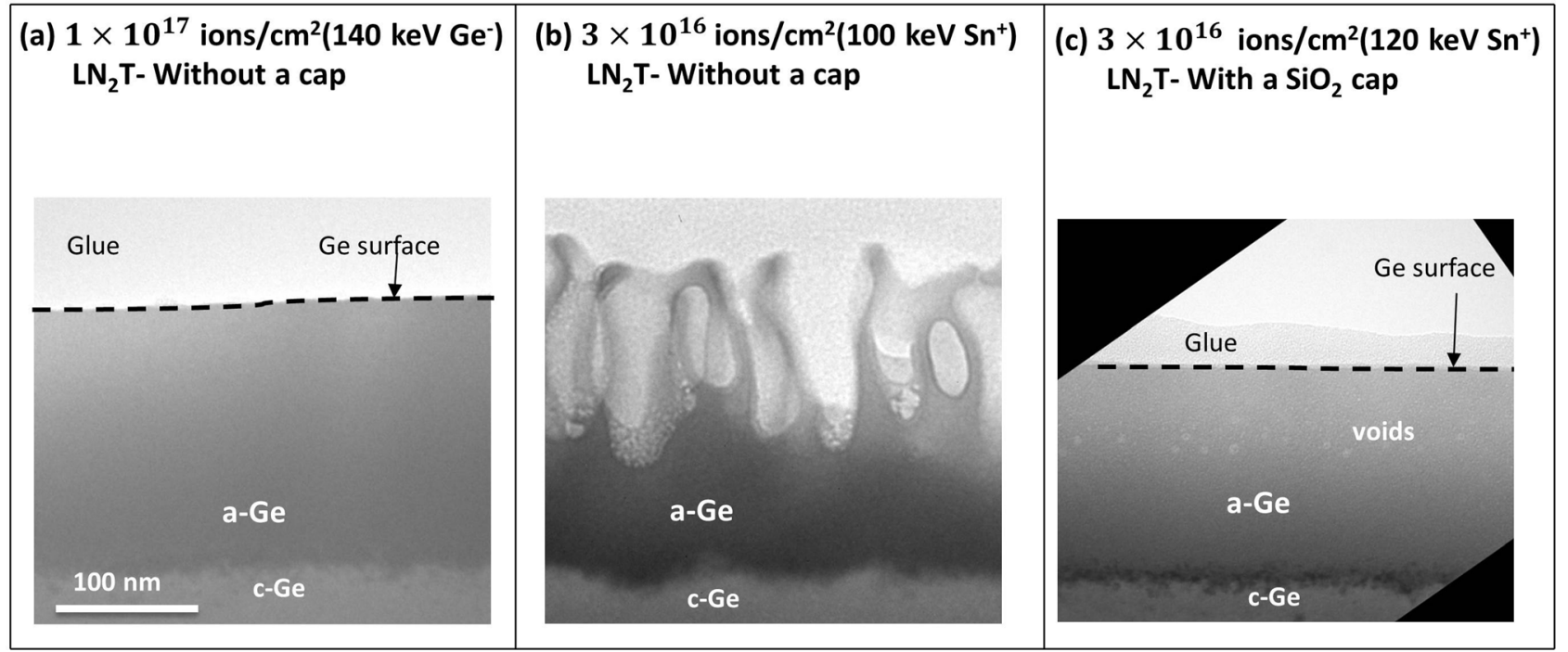

FIG. 1. XTEM images of Ge implanted with $\mathrm{Sn}$ and $\mathrm{Ge}$ ions at $\mathrm{LN}_{2} \mathrm{~T}$ with and without a $\mathrm{SiO}_{2}$ cap layer. (a) $1 \times 10^{17}$ ions $/ \mathrm{cm}^{2}$ with $140 \mathrm{keV} \mathrm{Ge}$ ions without a cap layer; (b) $3 \times 10^{16}$ ions $/ \mathrm{cm}^{2} 100 \mathrm{keV} \mathrm{Sn}{ }^{+}$ions without a cap; (c) $3 \times 10^{16}$ ions $/ \mathrm{cm}^{2} 120 \mathrm{keV} \mathrm{Sn}{ }^{+}$ions with a $\mathrm{SiO}_{2}$ cap layer; in (c), the cap layer has been removed prior to the XTEM analysis. The scale bar is the same for all XTEM images.

typical porosity microstructure in irradiated Ge. ${ }^{14,15}$ In contrast, capping the surface with a $\mathrm{SiO}_{2}$ layer of $20 \mathrm{~nm}$ thickness totally eliminated pore formation at $\mathrm{LN}_{2} \mathrm{~T}$ at the same Sn fluence as shown in Fig. 1(c). The implant energy of the Sn ions was slightly higher to account for energy loss due to penetration through the cap layer. However, a band of small voids is observed in the a-Ge layer, close to the depth of maximum energy deposition. As discussed previously, ${ }^{2}$ this band presumably arises from agglomeration of vacancies at the depth of maximum vacancy production rather than vacancy migration to the surface, where clustering and void formation appear to nucleate pores in the uncapped case. Comparing the $\mathrm{Ge}$ and $\mathrm{Sn}$ behaviours at $\mathrm{LN}_{2} \mathrm{~T}$, for uncapped samples, the heavier Sn ions cause pores to form, whereas Ge ions do not. The understanding of this behaviour in terms of the effect of higher nuclear energy loss and/ or chemical effects in case of $\mathrm{Sn}$ is treated in Sec. IV. Indeed, differences between the porous behaviour of the two ion species and the effect of a cap on the data of Fig. 1 were the motivations for the current study.

\section{A. Ion fluence dependence}

Figs. 2(a)-2(1) show PVSEM and XTEM micrographs following self-ion implantation of Ge with $140 \mathrm{keV}$ ions at RT with and without a cap layer of $\mathrm{SiO}_{2}$ at different fluences.

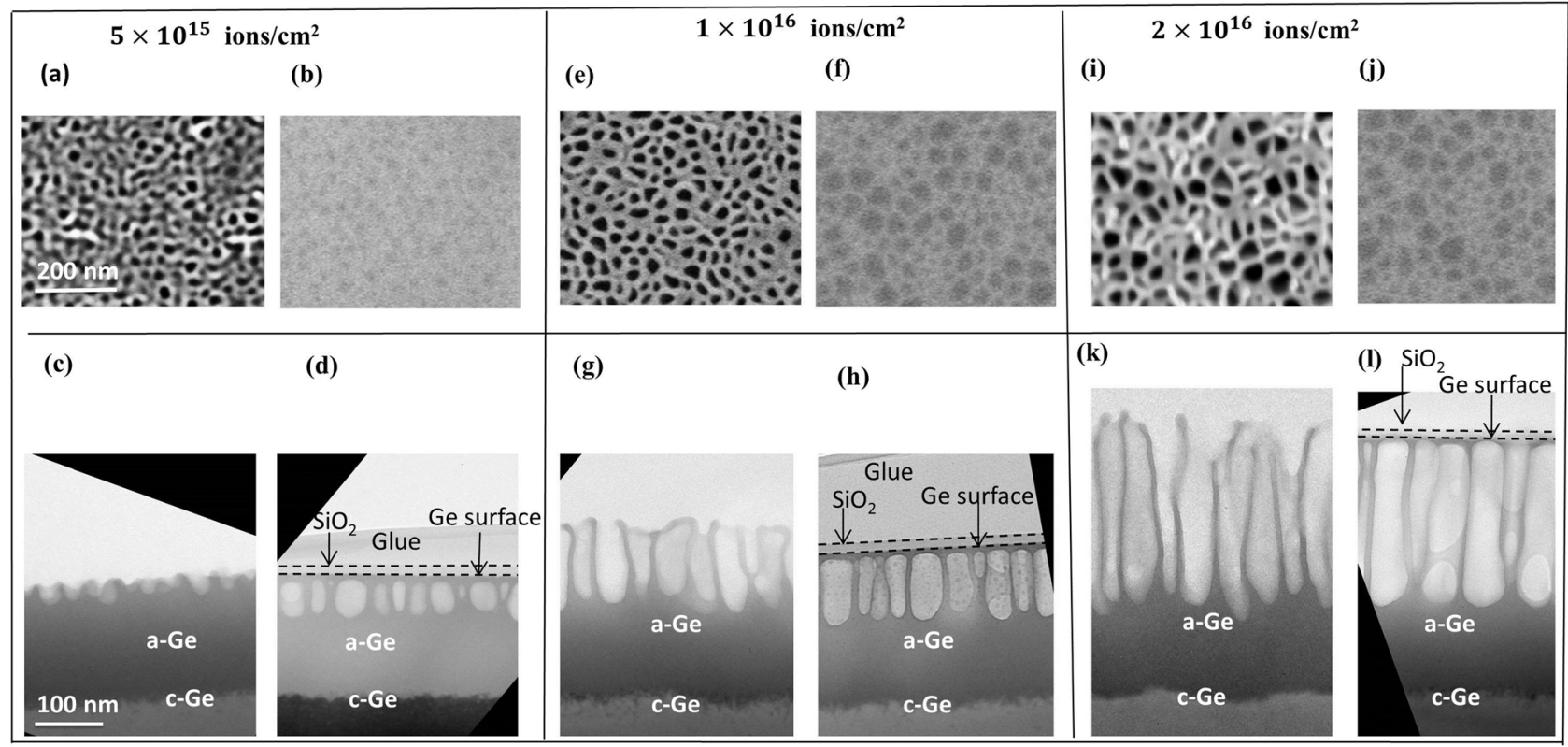

FIG. 2. PVSEM and XTEM images for different ion fluences for self-ion implantation of Ge with $140 \mathrm{keV}$ implanted at $\mathrm{RT}$ with a cap layer of $\mathrm{SiO}_{2}$ and without a cap layer; (a) and (c) $5 \times 10^{15}$ ions $/ \mathrm{cm}^{2}$ without a cap; (b) and (d) $5 \times 10^{15} \mathrm{ions} / \mathrm{cm}^{2}$ with $20 \mathrm{~nm}$ of a $\mathrm{SiO}_{2}$ layer; (e) and (g) $1 \times 10^{16}$ ions $/ \mathrm{cm}^{2}$ without a cap layer; (f) and (h) $1 \times 10^{16}$ ions $/ \mathrm{cm}^{2}$ with a cap layer; (i) and (k) $2 \times 10^{16}$ ions $/ \mathrm{cm}^{2}$ without a cap layer; (j) and (l) $2 \times 10^{16}$ ions $/ \mathrm{cm}^{2}$ with a cap layer; in (l), the cap layer partly has been removed due to sputtering. The scale bars in (a) and (c) are the same for all PVSEM and XTEM images, respectively. 
The evolution of the pore structure with fluence at RT with no cap is consistent with our previous results. For example, the pore structure appears to nucleate from voids at the surface at low fluence (Fig. 2(c)) and then extends as columns with thin walls as the fluence increases (Figs. 2(g) and 2(h)). The pore size increases slowly from 10 to $16 \mathrm{~nm}$ for fluences from $5 \times 10^{15}$ to $2 \times 10^{16}$ ions $/ \mathrm{cm}^{2}$ (Figs. 2(a), 2(e), and 2(i)). From the XTEM images in Fig. 2, it is clear that a porous structure in Ge both with a cap layer and without a cap layer forms in a-Ge at RT, consistent with prior understanding. ${ }^{15,17}$

For the capped samples, the evolution of a porous structure at RT, in terms of near surface void nucleation and development of a columnar structure, is essentially similar to uncapped samples. However, in all of the capped samples, there is a band of a-Ge immediately under the cap that is denuded of pores and is approximately $8 \mathrm{~nm}$ in thickness. This band suggests that vacancy agglomeration and pore formation are suppressed immediately below the cap layer, but it is surprising that this denuded layer does not change in thickness with fluence. Looking further at the detailed differences between capped and uncapped samples, it appears that at the low fluence of $5 \times 10^{15}$ ions $/ \mathrm{cm}^{2}$ (see Fig. 2(d)), the cap layer may actually contribute to an ordered porous structure once porosity develops, with larger voids apparent in the capped sample, but the voids do not extend to the surface. Furthermore, the porous structure for samples with a capping layer seems to be relatively uniform and well-ordered, with the individual pores more homogeneous in appearance and having walls that are mostly more vertical compared with the cases without the cap layer for almost all fluences (see
Figs. 2(d), 2(h), and 2(i)). Presumably, sputtering of the porous layer at the a-Ge surface in uncapped samples contributes to the observed less ordered columnar arrangement in such cases. In summary, when the cap layer is present prior to implantation, the porous structure still forms at RT, but there is a non-porous a-Ge barrier layer directly underneath the cap layer.

The fluence dependence of pore formation with Sn ions at RT, with and without a cap, is shown by the PVSEM and XTEM images in Figs. 3(a)-3(1). Basically, the pore evolution with Sn ion fluence is essentially similar to the case of $\mathrm{Ge}$ ions. It is interesting that the barrier layer denuded of pores is again around $8 \mathrm{~nm}$ in thickness, despite the heavier Sn ions and higher rate of nuclear energy deposition under the cap. Significant difference between $\mathrm{Sn}$ and $\mathrm{Ge}$ is that pore nucleation occurs at a lower ion fluence for heavier $\mathrm{Sn}$ ions. In addition, some patchy surface structures for the capped $\mathrm{Sn}$ implanted Ge samples at the two highest fluences are observed. We consider that this is due to effective sputter removal of portions of the $20 \mathrm{~nm}$ cap at such fluences, noting that a Sn fluence of $5 \times 10^{16}$ ions $/ \mathrm{cm}^{2}$ totally removes the cap. ${ }^{2}$

Figs. 4(a) and 4(b) show volumetric swelling as a function of implanted ion fluence with a $\mathrm{SiO}_{2}$ cap layer of $20 \mathrm{~nm}$ thickness and without a cap layer. Fig. 4(a) shows self-ion implantation of Ge irradiated at $140 \mathrm{keV}$, and Fig. 4(b) is for $\mathrm{Sn}$ ions irradiated at $225 \mathrm{keV}$. The data show swelling which increases with ion fluence for both ion species, and slightly less swelling for samples implanted with the cap layer. By comparing the step height in $\mathrm{Sn}$ to the one in $\mathrm{Ge}$, it is clear that the volumetric expansion in $\mathrm{Sn}(\sim 210 \mathrm{~nm})$ is much

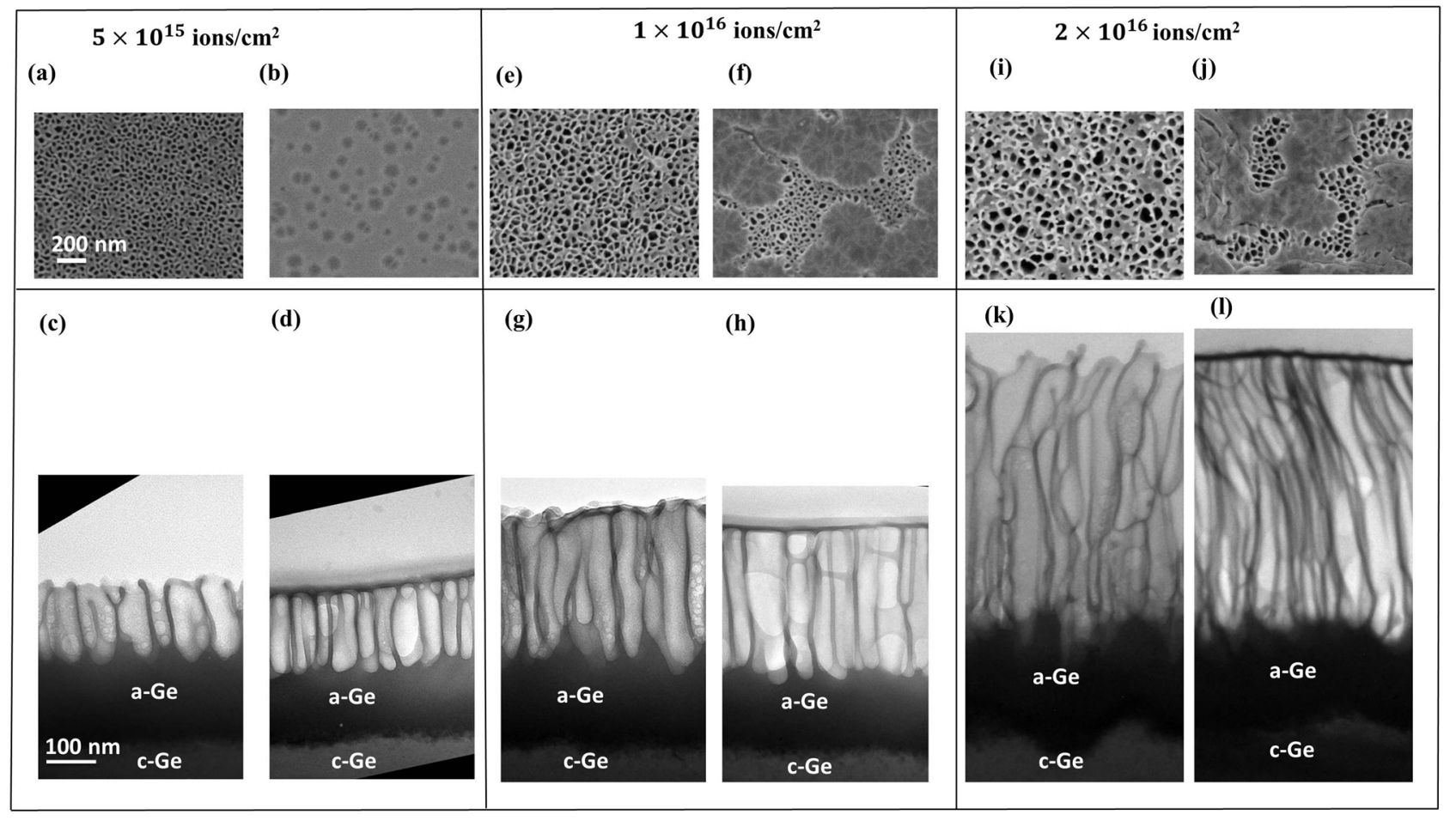

FIG. 3. PVSEM and XTEM images for different ion fluences for implanting Ge with $225 \mathrm{keV} \mathrm{Sn}^{+}$at RT with a $20 \mathrm{~nm} \mathrm{SiO}_{2}$ cap layer and without a cap layer; (a) and (c) $5 \times 10^{15}$ ions $/ \mathrm{cm}^{2}$ without a cap layer; (b) and (d) $5 \times 10^{15} \mathrm{ions} / \mathrm{cm}^{2}$ with a cap layer; (e) and (g) $1 \times 10^{16}$ ions $/ \mathrm{cm}^{2}$ without a cap layer; (f) and (h) $1 \times 10^{16}$ ions $/ \mathrm{cm}^{2}$ with a cap layer; (i) and (k) $2 \times 10^{16}$ ions $/ \mathrm{cm}^{2}$ without a cap layer; (j) and (l) $2 \times 10^{16}$ ions $/ \mathrm{cm}^{2}$ with a cap layer; in (l), the cap layer has been removed due to sputtering. The scale bars are the same in (a) and (c) for all PVSEM and XTEM images, respectively. 


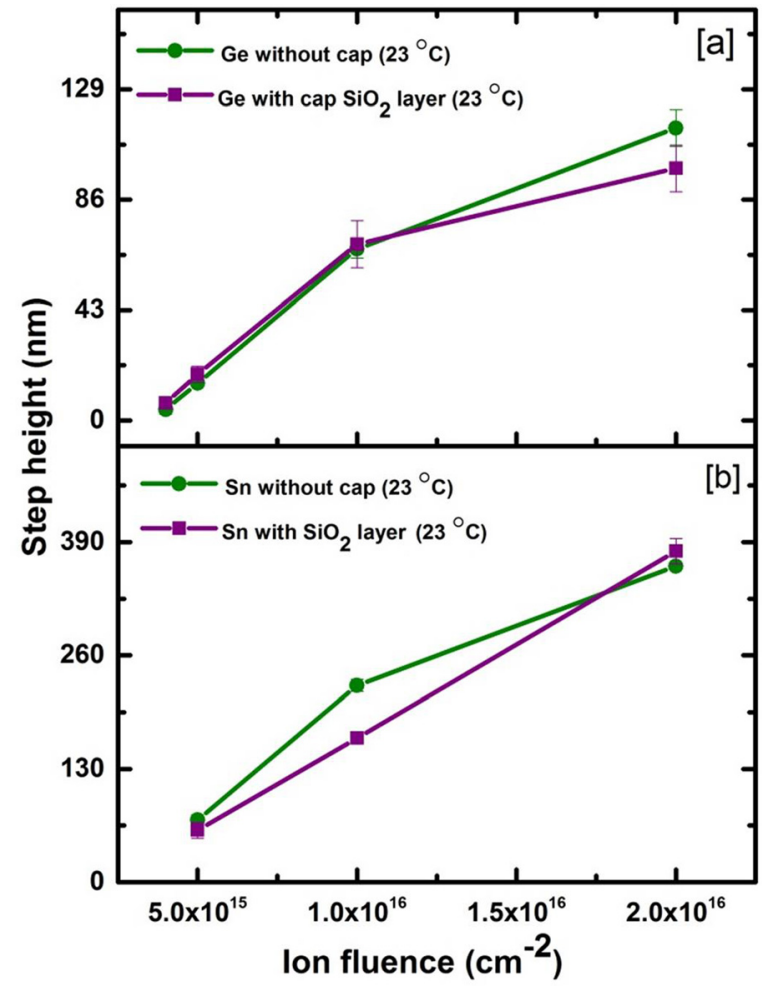

FIG. 4. Step height due to volumetric swelling as a function of implanted fluence in Ge implanted with $140 \mathrm{keV} \mathrm{Ge}^{-}$ions at RT with and without a $20 \mathrm{~nm} \mathrm{SiO}$ layer (a); and $\mathrm{Ge}$ implanted with $225 \mathrm{keV} \mathrm{Sn}^{+}$ions at RT with and without a $20 \mathrm{~nm} \mathrm{SiO}_{2}$ layer (b). larger than in $\mathrm{Ge}(\sim 120 \mathrm{~nm})$ at an implanted fluence of $2 \times 10^{16} \mathrm{ions} / \mathrm{cm}^{2}$. This effect may be due to the slightly higher projected ion range of $\mathrm{Sn}$ and the higher nuclear energy deposition which results in a thicker a-Ge layer (see Table I).

\section{B. Temperature dependence of porosity}

In this section, we highlight the effect of temperature on the pore formation with and without a $\mathrm{SiO}_{2}$ cap layer. One fluence has been selected $\left(2 \times 10^{16} \mathrm{ions} / \mathrm{cm}^{2}\right)$, with one thickness of cap layer $(20 \mathrm{~nm})$.

Figs. 5(a)-5(h) show PVSEM and XTEM images for self-ion implantation of $\mathrm{Ge}$ at $\mathrm{LN}_{2} \mathrm{~T}$ and $-50{ }^{\circ} \mathrm{C}$, with and without a $\mathrm{SiO}_{2}$ cap layer of $20 \mathrm{~nm}$ thickness. It is obvious that irradiation at $\mathrm{LN}_{2} \mathrm{~T}$ suppresses the porous structure regardless of the presence of a cap layer. This is consistent with the result in Fig. 1(a) at a much higher $\mathrm{Ge}^{-}$ion fluence. However, implanting at $-50^{\circ} \mathrm{C}$ without a cap layer develops a clear porous layer with a well-defined columnar structure with a thickness of $153 \mathrm{~nm}$ (see Figs. 5(e) and 5(g)) overlaying an a-Ge layer of similar thickness. In contrast, with a cap at $-50{ }^{\circ} \mathrm{C}$ there is clear suppression of a pore layer: the a-Ge is largely intact with occasional large voids under the cap as shown in Figs. 5(f) and 5(h).

In the case of Sn ions, Fig. 6 shows that no obvious porous structure is observed for both capped and uncapped samples under $\mathrm{LN}_{2} \mathrm{~T}$ at a fluence of $2 \times 10^{16} \mathrm{ions} / \mathrm{cm}^{2}$. We note that

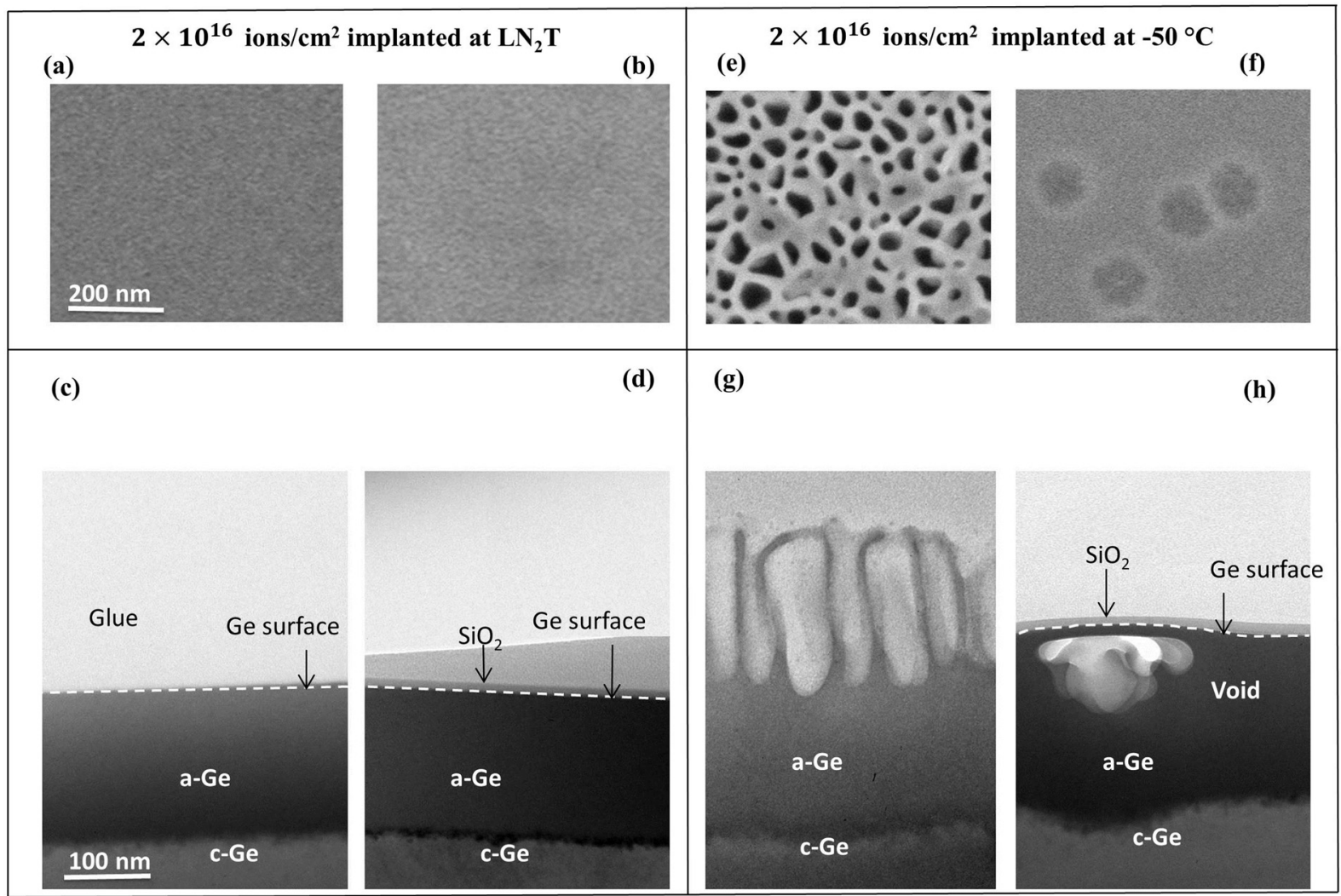

FIG. 5. PVSEM and XTEM images for Ge implanted with $140 \mathrm{keV} \mathrm{Ge}-$ ions under different temperatures with a $20 \mathrm{~nm} \mathrm{SiO}_{2}$ cap and without a cap layer; (a) and (c) $2 \times 10^{16}$ ions $/ \mathrm{cm}^{2}$ at $\mathrm{LN}_{2} \mathrm{~T}$ without a cap; (b) and (d) $2 \times 10^{16}$ ions $/ \mathrm{cm}^{2}$ at $\mathrm{LN}_{2} \mathrm{~T}$ with a cap layer;. (e) and (g) $2 \times 10^{16}$ ions/cm ${ }^{2}$ at $-50{ }^{\circ} \mathrm{C}$ without a cap layer; (f) and (h) $2 \times 10^{16}$ ions $/ \mathrm{cm}^{2}$ at $-50^{\circ} \mathrm{C}$ with a cap layer. The scale bars in (a) and (c) are the same for all PVSEM and XTEM images, respectively. 


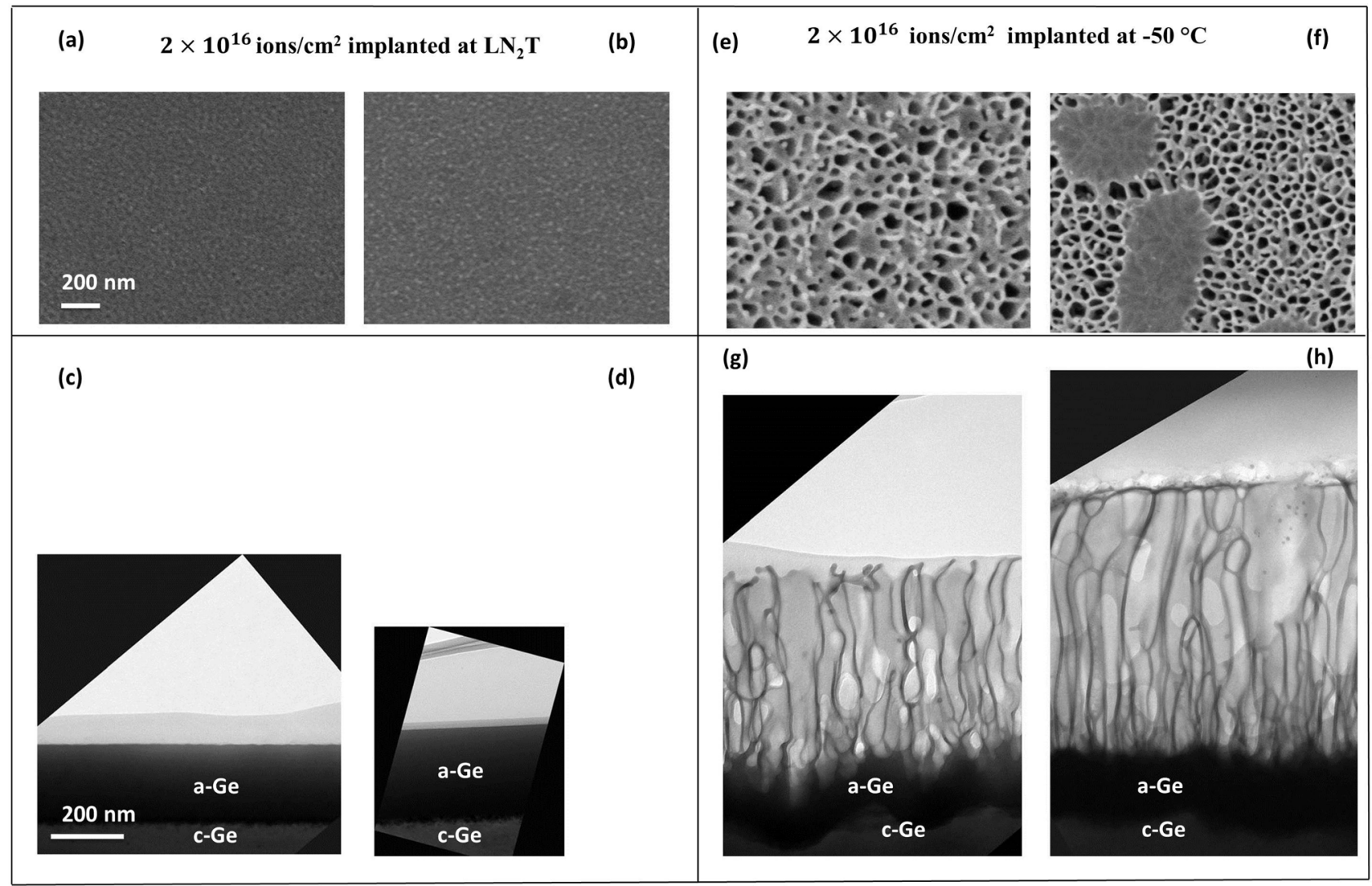

FIG. 6. PVSEM and XTEM images for Ge implanted with $225 \mathrm{keV} \mathrm{Sn}{ }^{+}$ions at different temperatures with a $20 \mathrm{~nm}$ cap layer of $\mathrm{SiO}_{2}$ and without a cap layer; (a) and (c) $2 \times 10^{16}$ ions $/ \mathrm{cm}^{2}$ at $\mathrm{LN}_{2} \mathrm{~T}$ without a cap; (b) and (d) $2 \times 10^{16}$ ions $/ \mathrm{cm}^{2}$ at $\mathrm{LN}_{2} \mathrm{~T}$ with a cap layer; (e) and (g) $2 \times 10^{16}$ ions $/ \mathrm{cm}^{2}$ at $-50^{\circ} \mathrm{C}$ without a cap; (f) and (h) $2 \times 10^{16}$ ions $/ \mathrm{cm}^{2}$ at $-50^{\circ} \mathrm{C}$ with a cap layer; in (h), the cap layer has been removed due to sputtering. The scale bars in (a) and (c) are the same for all PVSEM and XTEM images, respectively.

this fluence is just below the threshold fluence for pore formation with $\mathrm{Sn}$ ions since a fluence of $3 \times 10^{16} \mathrm{ions} / \mathrm{cm}^{2}$ gives rise to a clear porous structure as shown in Fig. 1(b) for the case without a $\mathrm{SiO}_{2}$ cap.

However, as the temperature is increased to $-50^{\circ} \mathrm{C}$, both capped and uncapped samples show the formation of a porous structure (see Figs. 6(e)-6(h)), indicating that, at this ion fluence $\left(2 \times 10^{16} \mathrm{ions} / \mathrm{cm}^{2}\right)$, the formation of a porous structure is not suppressed at $-50{ }^{\circ} \mathrm{C}$, regardless of the use of a cap layer. We note that at a lower $\mathrm{Sn}$ ion fluence of $5 \times 10^{15}$ ions $/ \mathrm{cm}^{2}$ at $-50{ }^{\circ} \mathrm{C}$ (not shown), a porous structure does not develop, only isolated large voids similar to the situation for Ge ions at higher fluence in Fig. 5(h). Thus, ion species, fluence, and irradiation temperature influence pore formation in Ge with and without a cap layer.

In summary, there are significant differences between $\mathrm{Sn}$ and Ge ions in terms of development of a porous structure in Ge. The first difference is at $\mathrm{LN}_{2} \mathrm{~T}$, where a porous structure is always suppressed with Ge ions even at very high fluences with or without a cap layer. However, with Sn ions without a cap layer, a porous structure is not suppressed if the ion fluence is above a threshold fluence which is around $2.5-3 \times 10^{16}$ ions $/ \mathrm{cm}^{2}$. However, by coating the surface with a $\mathrm{SiO}_{2}$ film, porosity is suppressed at high $\mathrm{Sn}$ ion fluences well above the threshold for porous development without a cap. Second, if the temperature is increased to $-50^{\circ} \mathrm{C}$, a porous structure occurs in $\mathrm{Ge}$ at a $\mathrm{Sn}$ ion fluence of $2 \times 10^{16} \mathrm{ions} / \mathrm{cm}^{2}$ both with and without a cap, but the situation with $\mathrm{Ge}$ ions is quite different. Pore formation fully develops at $2 \times 10^{16} \mathrm{Ge}^{-}$ions $/ \mathrm{cm}^{2}$ without a cap, whereas the a-Ge layer is largely intact at this fluence with occasional large voids when a cap layer is used. This suggests that, if the fluence is increased beyond $2 \times 10^{16}$ ions $/ \mathrm{cm}^{2}$ in this latter case, pore formation may fully develop. Hence, both the ion fluence and the temperature are playing an important role in terms of suppressing or enhancing the development of a porous structure with and without a cap layer, and for heavier ions the onset of porosity occurs at a lower fluence.

Fig. 7 shows the volumetric expansion as a function of implant temperature for irradiation of $\mathrm{Ge}$ with both $\mathrm{Ge}$ (a) and Sn (b) ions, with and without a cap. In Fig. 7(a), the measured step height is consistent with the TEM results. At $\mathrm{LN}_{2} \mathrm{~T}$, with Ge ions the swelling is less than $1 \mathrm{~nm}$ consistent with a thick a-Ge layer with no porosity. When the temperature increases to $-50{ }^{\circ} \mathrm{C}$, the step height is shown to be $65 \mathrm{~nm}$ for the samples without a cap, but only $3.9 \mathrm{~nm}$ for the samples with such a cap. This is again consistent with the XTEM results in Fig. 5 where occasional large voids are observed with a cap, whereas a decidedly porous structure occurs without a cap. In the case of Sn in Fig. 7(b), the step height shows no swelling at $\mathrm{LN}_{2} \mathrm{~T}$ for both capped and uncapped samples, consistent with no porous structure observed in XTEM images. However, implantation at $\geq-50^{\circ} \mathrm{C}$ and $\mathrm{RT}$ develops a porous structure regardless of a 


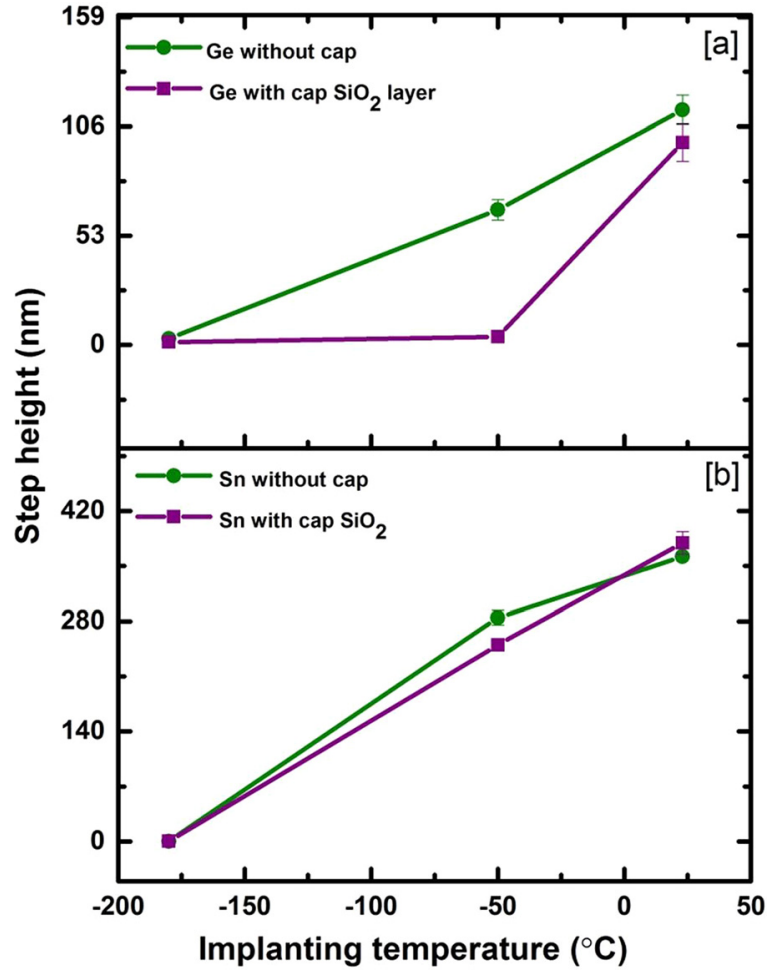

FIG. 7. Volumetric swelling as a function of implantation temperature in $\mathrm{Ge}$ for $\mathrm{Ge}$ and $\mathrm{Sn}$ ions at a fluence of $2 \times 10^{16} \mathrm{ions} / \mathrm{cm}^{2}$; (a) $140 \mathrm{keV} \mathrm{Ge}$ ions with and without a cap layer of $20 \mathrm{~nm} \mathrm{SiO}_{2}$; (b) $225 \mathrm{keV} \mathrm{Sn}^{+}$ions with and without a cap layer of $20 \mathrm{~nm} \mathrm{SiO}_{2}$.

cap layer and the swelling is essentially the same for cap and no cap cases.

\section{The effect of cap layer thickness}

To study the effects of cap layer thickness, two thicknesses of the cap layer $\left(20 \mathrm{~nm}\right.$ and $40 \mathrm{~nm}$ of $\left.\mathrm{SiO}_{2}\right)$ were deposited onto $\mathrm{Ge}$ prior to implantation and a fluence of $1 \times 10^{16}$ ions $/ \mathrm{cm}^{2}$ was selected at RT for both Ge and Sn ions.

Fig. 8 shows XTEM images for Ge capped with $40 \mathrm{~nm}$ of $\mathrm{SiO}_{2}$ and implanted with both $\mathrm{Ge}$ and $\mathrm{Sn}$ ions to a fluence of $1 \times 10^{16}$ ions $/ \mathrm{cm}^{2}$ at RT. These images should be compared with Figs. 2(h) and 3(h) for a $20 \mathrm{~nm} \mathrm{SiO}_{2}$ cap layer. The only significant change observed was a reduction in the porous layer thickness for both Ge and $\mathrm{Sn}$ ions for the $40 \mathrm{~nm}$ layer compared with the $20 \mathrm{~nm}$ layer. The cap layer thickness does not show any significant difference in terms of porous layer formation, pore diameter, and degree of swelling, which is in good agreement with earlier studies of Janssens et al. for Sb bombarded Ge. ${ }^{17}$ We note that the layer of a-Ge denuded of pores directly under the cap layer remains close to $8 \mathrm{~nm}$ thick regardless of the cap thickness.

\section{DISCUSSION}

Overall, there are clear trends obtained from this study relating to the formation and evolution of porosity in ion irradiated Ge. The data are consistent with previous studies, where there are clear dependencies on ion fluence and temperature. In terms of ion fluence, there is a threshold fluence above which porosity nucleates and develops in ion

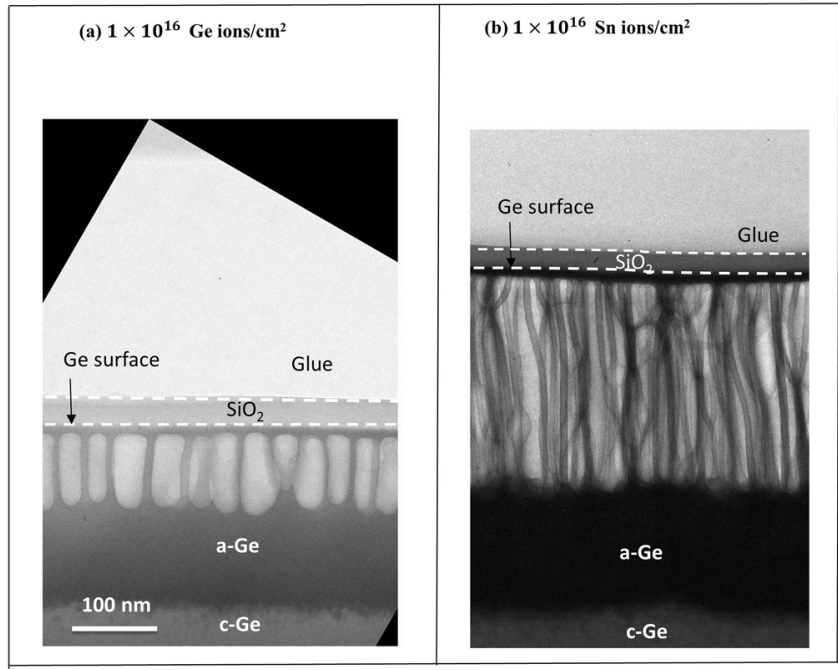

FIG. 8. XTEM images for a selected fluence of $1 \times 10^{16}$ ions $/ \mathrm{cm}^{2}$ for $40 \mathrm{~nm}$ thickness of a cap layer implanted at RT (a) $140 \mathrm{keV} \mathrm{Ge}^{-}$ions; (b) $225 \mathrm{keV}$ $\mathrm{Sn}^{+}$ions. The scale bar is the same for both XTEM images.

amorphized Ge. In addition, for each ion species there appears to be a temperature range in which porosity is favored: below this window, porosity is difficult or impossible to develop even at extremely high ion fluence, and above this window, Ge cannot be rendered amorphous which is a prerequisite for pore formation. ${ }^{5}$ We have also observed a significant ion species dependence, whereby the heavier ion Sn clearly promotes pore formation at lower temperatures compared with Ge ions, noting that $\mathrm{Ge}$ ion irradiation cannot initiate pores in $\mathrm{Ge}$ at any fluence at $\mathrm{LN}_{2} \mathrm{~T}$, whereas $\mathrm{Sn}$ ion irradiation can initiate porosity at moderate fluences $\left(>2 \times 10^{16}\right.$ ions $\left./ \mathrm{cm}^{2}\right)$ at this temperature (Fig. 1). We have insufficient data to establish whether this species effect is caused by the higher nuclear energy deposition of Sn ions (higher density of vacancies produced along ion tracks) or whether chemistry plays a role. For example, does a higher vacancy production rate favor agglomeration of vacancies into voids even at $\mathrm{LN}_{2} \mathrm{~T}$ or does $\mathrm{Sn}$ (when its concentration builds up to several atomic percent) enhance vacancy migration and/or agglomeration via a chemical effect as suggested in our recent publication? ${ }^{2}$ Further studies, for example, with a wider range of ion species, would be needed to resolve this issue.

In terms of an $\mathrm{SiO}_{2}$ capping layer, its effect in retarding porosity is apparent in some cases in the data presented, but the role of the cap in influencing vacancy agglomeration (at the cap-Ge interface for example) appears to be quite complex. Clearly, in the case of both $\mathrm{Sn}$ and Ge ions at low temperatures, the presence of a $\mathrm{SiO}_{2}$ cap suppresses porosity, appearing to substantially increase the threshold fluence for the development of porous layers (at $\mathrm{LN}_{2} \mathrm{~T}$ for $\mathrm{Sn}$ ions and at $-50{ }^{\circ} \mathrm{C}$ for $\mathrm{Ge}$ ions). This conclusion is supported by the fact that, at the same $3 \times 10^{16}$ ions $/ \mathrm{cm}^{2}$, fluence at $\mathrm{LN}_{2} \mathrm{~T} \mathrm{Sn}$ ions causes a well-developed porous layer without a cap, whereas only small voids are observed with a cap (Figs. 1(b) and 1(c)). For Ge ions, this behavior appears at a higher temperature $\left(-50^{\circ} \mathrm{C}\right)$ as shown in Figs. 5(g) and 5(h). At RT, where a cap does not significantly suppress porosity (at least under the ion fluence/species conditions in this study), there is actually 
evidence that once porosity is initiated, a $\mathrm{SiO}_{2}$ cap may facilitate its development into an ordered structure (see Figs. 2(c) and 2(d)). Another effect of a cap is that it suppresses sputtering of the underlying Ge layer and this lack of sputtering may contribute to the more ordered porous structure. To help understand why a cap can suppress porosity particularly at low temperature, it is important to review the understanding of the nucleation of pores in a-Ge under ion irradiation. For $\mathrm{keV}$ ion irradiation, there is now considerable evidence in the literature that vacancy agglomeration first occurs at the $\mathrm{Ge}$ surface (in uncapped samples) rather than at the peak of the nuclear energy deposition density (maximum in vacancy production) ${ }^{14}$ Further details of the vacancy clustering mechanism of porous formation and vacancy migration to the surface can be found in Refs. 9, 14, 15, and 21. Indeed, in Fig. 2(c), it is clear that voids develop first at the Ge surface at a low fluence of $5 \times 10^{15}$ ions $/ \mathrm{cm}^{2}$ at RT. In contrast, when a cap is used, the surface of the Ge in contact with the cap appears denuded of voids and Fig. 1(c) shows that voids nucleate deeper in the a-Ge layer (at least for the $\mathrm{LN}_{2} \mathrm{~T} \mathrm{Sn}$ irradiation case). This may suggest that a cap layer suppresses vacancy agglomeration at the Ge surface, the region where pores nucleate in the uncapped case, thus raising the critical fluence for nucleation of pores. Alternatively, the presence of a mechanically more rigid cap at lower irradiation temperatures may restrict the viscous flow of underlying a-Ge under irradiation and hence inhibit expansion of the a-Ge layer, thus suppressing vacancy agglomeration. We note that the viscous flow of both a- $\mathrm{Si}^{22,23}$ and a- $\mathrm{Ge}^{23,24}$ materials has previously been observed under ion irradiation. We explore below both this issue and possible reasons for the lack of void formation in a continuous a-Ge barrier layer directly below a $\mathrm{SiO}_{2}$ cap layer.

The barrier layer denuded of pores directly under the cap has a constant thickness of $\sim 8 \mathrm{~nm}$ regardless of ion fluence, energy, mass, or temperature. Even if the temperature is raised to $100^{\circ} \mathrm{C}$ as is shown in Fig. 9, the thickness of the barrier layer does not change significantly. In the literature, there are few data with XTEM images of porosity under a cap layer. Indeed, Appleton et al. ${ }^{8}$ and Janssens et al. ${ }^{17}$ reported that pore formation does not extend to the surface when a cap layer is present, but they do not clearly demonstrate a barrier layer under a cap. However, in the work by Darby et al., ${ }^{18,19}$ there appears to be a clear pore-free layer with the same thickness as in our case in deposited Ge layers on $\mathrm{SiO}_{2}$ following ion irradiation. No explanation was given as to the origin of such layers in this case.

What then is the explanation for the formation of such a barrier layer between the cap and a porous subsurface layer? First, this layer could be the result of ion-induced intermixing of $\mathrm{Si}$ and $\mathrm{O}$ with the underlying Ge layer. To explore such intermixing, Fig. 10(a) shows two EDX spectra of the Si and $\mathrm{O}$ distribution in the underlying $\mathrm{Ge}$, indicating significant intermixing of $\mathrm{O}$ and $\mathrm{Si}$ directly below the cap compared with $\mathrm{O}$ and $\mathrm{Si}$ concentrations at depths below the porous layer. It could be that significant $\mathrm{O}$ (and $\mathrm{Si}$ ) in a-Ge could inhibit vacancy agglomeration under the cap layer. Indeed, we have previously shown that porosity is suppressed in $\mathrm{Si}_{1-\mathrm{x}} \mathrm{Ge}_{\mathrm{x}}$ alloys as the Si content increases. ${ }^{15}$ Janssens et al. also found

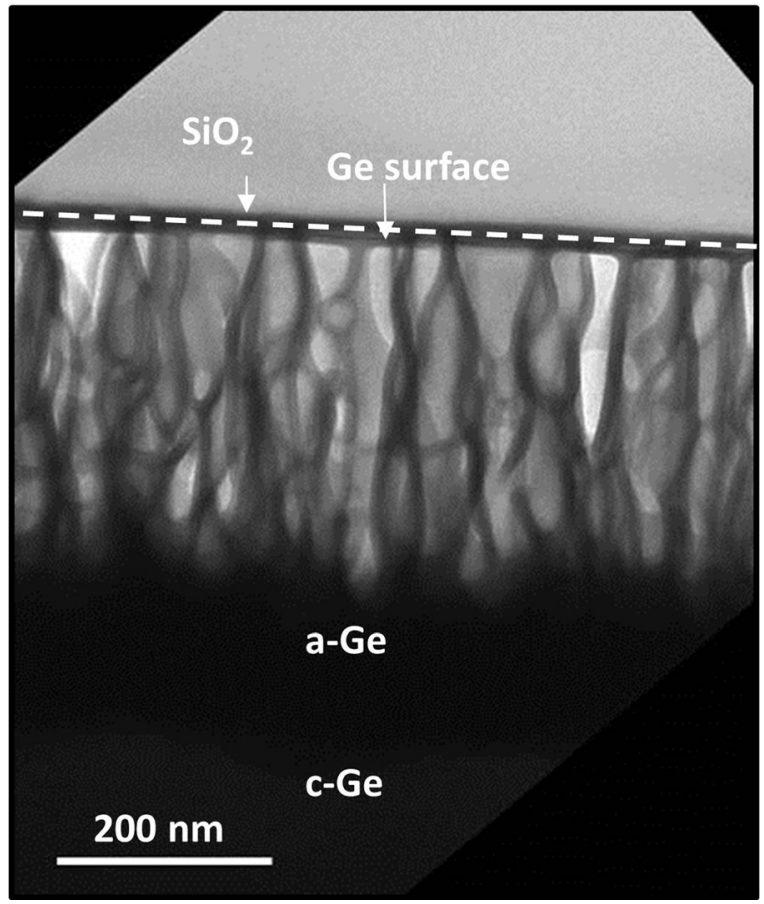

FIG. 9. XTEM images for a fluence of $2 \times 10^{16} \mathrm{ions} / \mathrm{cm}^{2}$ implanted into Ge with $140 \mathrm{keV} \mathrm{Ge}^{-}$at $100^{\circ} \mathrm{C}$. The cap layer has been removed due to sputtering.

that subsurface regions contain a large amount of $\mathrm{O}$ under a $\mathrm{SiO}_{2}$ cap. ${ }^{17}$ However, we would expect the degree of intermixing and $\mathrm{O} / \mathrm{Si}$ concentration-depth distributions to be significantly different as a function of ion species (that is, for Ge and heavier Sn ion irradiations) and at different fluences. In contrast, the barrier layer thickness remains constant, independent of ion species and fluence. Therefore, we do not believe that intermixing is the sole explanation for a barrier layer of constant thickness under a cap which is denuded of pores.

Different cap layer materials have been used to investigate if this denuded layer depends on the type of cap material or not. To examine such effects, different cap layers have been used such as metallic $\mathrm{Al}$ and a-Si. Typical results after irradiation with Ge ions are shown in Figs. 11(a)-11(d). Interestingly, the barrier layer thickness does not change from $\sim 8 \mathrm{~nm}$ in either case. In addition, since the barrier layer thickness is independent of the type of cap layer used, this reinforces the conclusion that intermixing is not the sole cause of a barrier layer denuded of pores.

Therefore, we have sought a more plausible explanation and propose that the a-Ge layer under the cap that remains denuded of pores is primarily a result of wetting of the cap by a-Ge under ion irradiation. We suggest that the denuded layer is the result of a process of minimisation of surface or interfacial free energy. First, it is well known that, under ion irradiation, a-Si and a-Ge experience the viscous flow. ${ }^{22-24}$ Indeed, material flow is one of the mechanisms by which lower density a-Ge/a-Si expands outwards from the surface under ion irradiation, a process driven by stress minimization and mediated by broken bond and defect motion within the amorphous phase. ${ }^{22}$ Also, when a-Ge goes porous, the further dramatic expansion of the porous layer is clearly assisted by the viscous flow of the amorphous phase. Hence, 

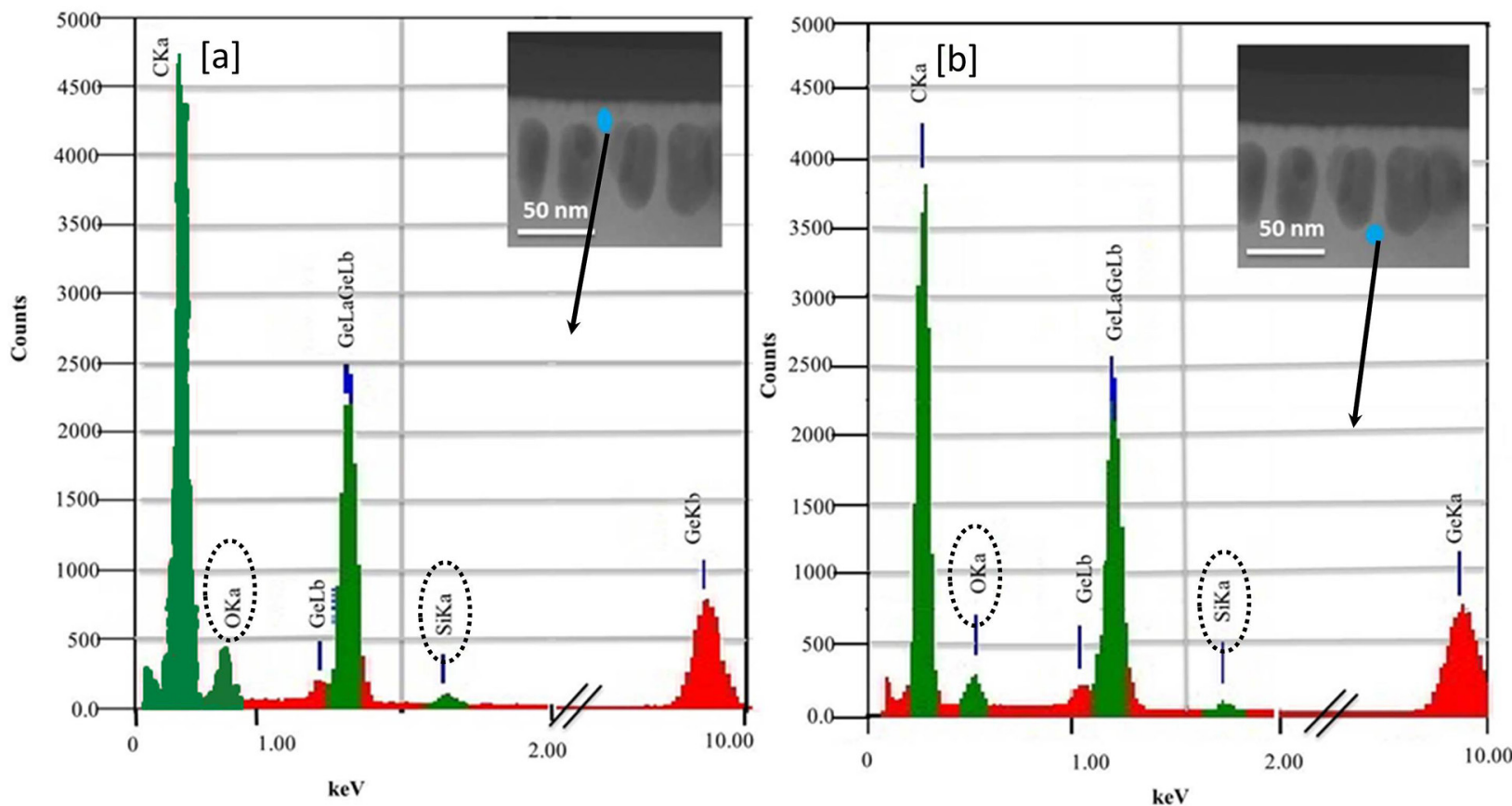

FIG. 10. EDX spectra for $5 \times 10^{15} \mathrm{Ge}$ ions $/ \mathrm{cm}^{2}$ through a $20 \mathrm{~nm} \mathrm{SiO}{ }_{2}$ cap layer. (a) EDX performed in the barrier layer and (b) EDX performed far from the surface.

it might be expected that the presence of a mechanically strong cap may inhibit expansion of a-Ge and thus suppress porosity. Indeed, this is the case at temperatures below room

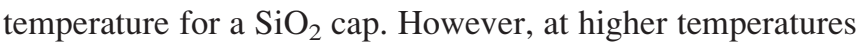
lower mechanical strength may cause the cap to flow under ion irradiation, as is the case for $\mathrm{SiO}_{2}$ and a-Si materials ${ }^{22,25}$ and almost certainly true for metallic Al. In such cases, there will now be no impediment to expansion of the underlying
a-Ge and development of porosity. We also suggest that interfacial free energy minimisation and wetting processes will control the behaviour of a-Ge material directly under the cap. In this regard, Hu et al. ${ }^{26,27}$ reported on the case of dewetting of a deposited $\mathrm{Pt}$ layer on $\mathrm{SiO}_{2}$ under irradiation with $800 \mathrm{keV} \mathrm{Kr}^{+}$ions. This dewetting phenomenon was attributed to the minimisation of free energy, resulting in the formation of large Pt droplets on the surface with large regions

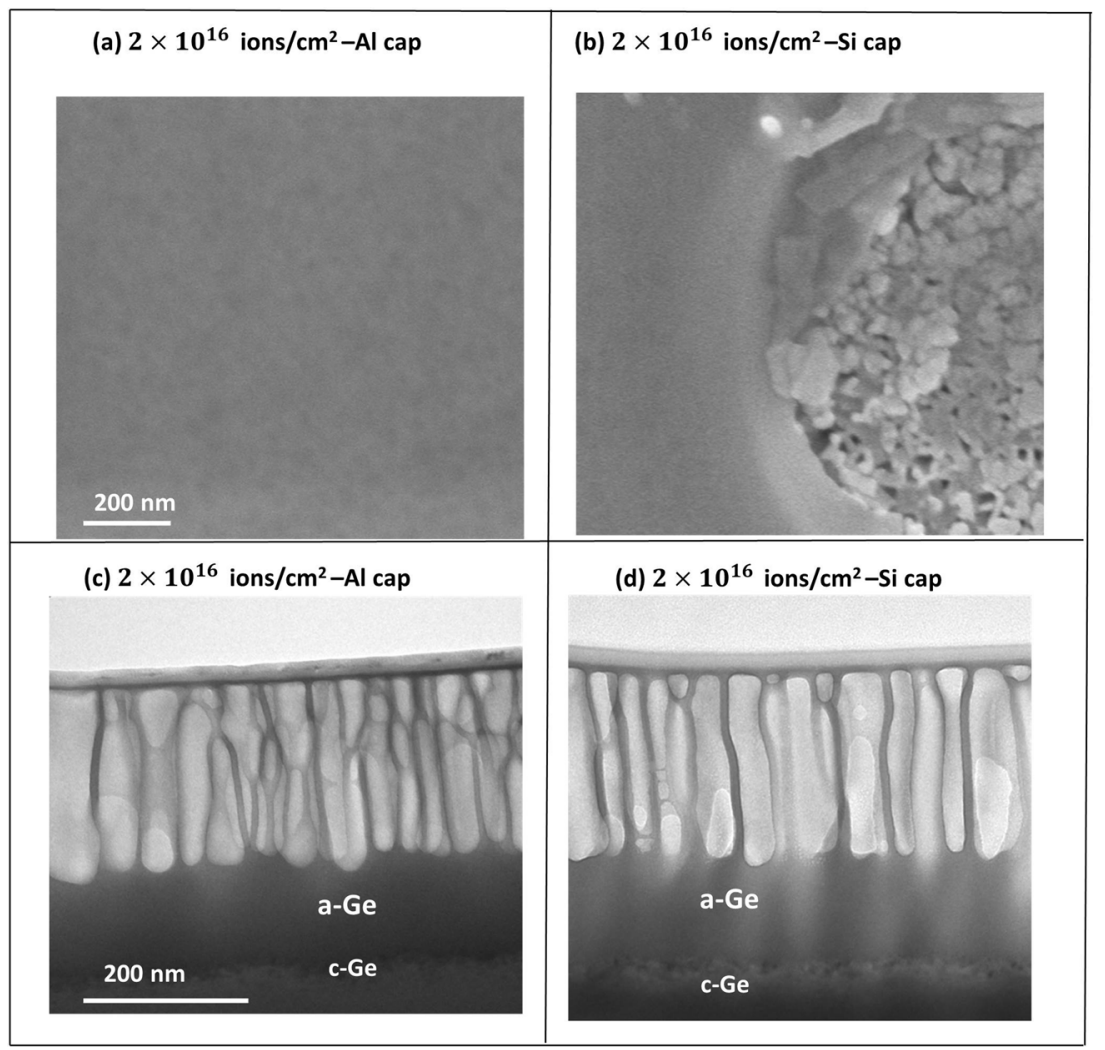

FIG. 11. PVSEM and XTEM images of $2 \times 10^{16} \mathrm{ions} / \mathrm{cm}^{2} 140 \mathrm{keV} \mathrm{Ge}$ ions with different cap layers $(40 \mathrm{~nm}$ thickness) at RT; (a) and (c) Al cap layer; (b) and (d) a-Si cap layer. The scale bar is the same for all PVSEM and XTEM images. 
free of Pt between them. Hence, in our case we suggest that the opposite, wetting phenomenon is operative: stress and viscous flow under irradiation ${ }^{23,26,27}$ will drive a-Ge towards the cap layer and wetting and free energy minimisation will control the thickness of a pore-free a-Ge layer under the cap. In addition, once pores form, atomic diffusion at the pore surfaces, and possibly sputtering from the pore walls, may also assist the transport of material towards the cap layer where interfacial minimum free energy considerations (wetting) under the cap will then apply. Consequently, as long as a-Ge wets the cap under the irradiation conditions of this study, the layer denuded of pores will not exhibit any dependence on ion fluence, ion species, thickness and type of the cap layer, and temperature, as is observed experimentally. However, it might be expected that cap materials exist which can cause insufficient wetting (or even dewetting) of a-Ge. Thus, a much wider range of capping materials could be investigated to study the nature of the barrier layer when strong wetting does not occur. We note that the walls of the porous structure, regardless of the presence of a cap, are also denuded of voids and are of a similar thickness to the denuded layer under the cap. However, the walls of pores, once formed, may be sustained by atomic diffusion within the walls and redeposition of material sputtered from the pore bottom, as previously suggested ${ }^{15}$ such that the mechanisms that control wall thickness maybe entirely different to that of a-Ge layers under a cap. Clearly, further experiments and calculations will be needed to fully explore this intriguing process of a-Ge flow and wetting of a cap layer.

\section{CONCLUSIONS}

In this study, we find that there is a significant dependence of pore formation on ion species. Heavier Sn ions promote porosity at $\mathrm{LN}_{2} \mathrm{~T}$ at a threshold fluence of $>2 \times 10^{16}$ ions $/ \mathrm{cm}^{2}$, whereas $\mathrm{Ge}$ ions do not give rise to porosity at $\mathrm{LN}_{2} \mathrm{~T}$ even at fluences of $>1 \times 10^{17}$ ions $/ \mathrm{cm}^{2}$. Surprisingly, the presence of a cap layer can eliminate pore formation for both $\mathrm{Sn}$ and $\mathrm{Ge}$ ions if the irradiation is conducted below both a critical temperature and ion fluence. However, at RT, a cap appears to allow development of a porous layer that is well-ordered and uniform compared to uncapped samples. This is attributed to the cap layer significantly reducing sputtering in the underlying a-Ge layer. Moreover, we have observed a barrier layer denuded of pores of constant $8 \mathrm{~nm}$ thickness directly under the cap layer, independent of ion fluence, temperature, ion species, and type of cap. We suggest that this pore-free layer is due to the viscous flow of a-Ge during ion irradiation and wetting of the cap layer as a result of minimization of the interfacial free energy.

\section{ACKNOWLEDGMENTS}

We acknowledge the access to the NCRIS and AMMRF infrastructure at the Australian National University including the Heavy Ion Accelerator Capability, the Center for Advanced Microscopy, and the ANFF ACT Node facility. We also thank the Australian Research Council and Dammam University for the financial support.

${ }^{1}$ A. L. Stepanov, V. V. Vorobev, Y. N. Osin, M. A. Ermakov, V. F. Valeev, and V. I. Nuzhdin, Sci. J. Microelectron. 4(3), 11-17 (2014).

${ }^{2}$ T. T. Tran, H. S. Alkhaldi, H. H. Gandhi, D. Pastor, L. Q. Huston, J. Wong-Leung, M. J. Aziz, and J. S. Williams, Appl. Phys. Lett. 109(8), 082106 (2016).

${ }^{3}$ M. R. Baklanov and K. Maex, Philos. Trans. R. Soc. London, Ser. A 364(1838), 201-215 (2006).

${ }^{4}$ I. H. Wilson, J. Appl. Phys. 53(3), 1698 (1982).

${ }^{5}$ B. Stritzker, R. G. Elliman, and J. Zou, Nucl. Instrum. Methods Phys. Res., Sect. B. 175-177, 193-196 (2001).

${ }^{6}$ L. Romano, G. Impellizzeri, L. Bosco, F. Ruffino, M. Miritello, and M. G. Grimaldi, J. Appl. Phys. 111(11), 113515 (2012).

${ }^{7}$ A. Belafhaili, L. Laânab, F. Cristiano, N. Cherkashin, and A. Claverie, Mater. Sci. Semicond. Process 16(6), 1655-1658 (2013).

${ }^{8}$ B. R. Appleton, O. W. Holland, D. B. Poker, J. Narayan, and D. Fathy, Nucl. Instrum. Methods Phys. Res., Sect. B 7-8 (MAR), 639-644 (1985).

${ }^{9}$ B. L. Darby, B. R. Yates, N. G. Rudawski, K. S. Jones, A. Kontos, and R. G. Elliman, Thin Solid Films 519(18), 5962-5965 (2011).

${ }^{10}$ N. G. Rudawski, B. L. Darby, B. R. Yates, K. S. Jones, R. G. Elliman, and A. A. Volinsky, Appl. Phys. Lett. 100(8), 083111 (2012).

${ }^{11}$ M. E. Davis, Nature 417(6891), 813-821 (2002).

${ }^{12}$ J.-H. Lee and J. C. Grossman, Appl. Phys. Lett. 95(1), 013106 (2009).

${ }^{13}$ G. Q. Lu and X. S. Zhao, Nanoporous Materials Science and Engineering (Imperial College Press, London, 2004).

${ }^{14}$ O. W. Holland, B. R. Appleton, and J. Narayan, J. Appl. Phys. 54(5), 2295 (1983).

${ }^{15}$ H. S. Alkhaldi, F. Kremer, T. Bierschenk, J. L. Hansen, A. NylandstedLarsen, J. S. Williams, and M. C. Ridgway, J. Appl. Phys. 119(9), 094303 (2016).

${ }^{16}$ E. Bruno, G. G. Scapellato, G. Bisognin, E. Carria, L. Romano, A. Carnera, and F. Priolo, J. Appl. Phys. 108(12), 124902 (2010).

${ }^{17}$ T. Janssens, C. Huyghebaert, D. Vanhaeren, G. Winderickx, A. Satta, M. Meuris, and W. Vandervorst, J. Vac. Sci. Technol., B 24(1), 510 (2006).

${ }^{18}$ B. L. Darby, Ph.D. thesis, University of Florida, 2012.

${ }^{19}$ B. Yates, B. Darby, R. Elliman, and K. Jones, Appl. Phys. Lett. 101(13), 131907 (2012).

${ }^{20}$ J. F. Ziegler, J. P. Biersack, and U. Littmark, The Stopping and Range of Ions in Solids (Pergamon, New York, 1984).

${ }^{21}$ L. Romano, G. Impellizzeri, M. V. Tomasello, F. Giannazzo, C. Spinella, and M. G. Grimaldi, J. Appl. Phys. 107(8), 084314 (2010).

${ }^{22}$ C. A. Volkert, J. Appl. Phys. 70(7), 3521-3527 (1991).

${ }^{23}$ A. Witvrouw and F. Spaepen, J. Appl. Phys. 74(12), 7154-7161 (1993).

${ }^{24}$ S. Mayr and R. Averback, Phys. Rev. B: Condens. Matter 71(13), 134102 (2005).

${ }^{25}$ E. Snoeks, A. Polman, and C. Volkert, Appl. Phys. Lett. 65(19), 2487-2489 (1994).

${ }^{26}$ X. Hu, D. G. Cahill, and R. S. Averback, J. Appl. Phys. 89(12), 7777-7783 (2001).

${ }^{27}$ X. Hu, D. G. Cahill, and R. S. Averback, Appl. Phys. Lett. 76(22), 3215 (2000). 